\title{
Survey of airflow around multiple buildings
}

\author{
Ahmed A. Rizk ${ }^{1,2}$, Gregor P. Henze ${ }^{3}$ \\ ${ }^{1}$ Architectural Engineering Department, Faculty of Engineering, University of Tanta, Egypt \\ ${ }^{2}$ Visiting Professor of Architectural Engineering, University of Nebraska - Lincoln, South 67th Street, Peter Kiewit Institute, Omaha, NE \\ ${ }^{3}$ University of Colorado at Boulder, CEAE Department 4228 UCB, Boulder, Colorado 80309-0428 U.S.A
}

\section{Email address:}

rizk2003@yahoo.com(A. A. Rizk), Gregor.Henze@Colorado.EDU(G. P. Henze)

\section{To cite this article:}

Ahmed A. Rizk, Gregor P. Henze. Survey of Airflow around Multiple Buildings. American Journal of Energy Engineering.

Vol. 2, No. 1, 2014, pp. 27-36. doi: 10.11648/j.ajee.20140201.14

\begin{abstract}
This survey paper offers a review of past and present studies related to air flow around multiple building configurations to achieve energy savings and thermal comfort in hot climate regions in the presence of increased urbanization. The purpose of this review paper is to provide guidelines based on previous studies for the successful design of group housing in a hot and arid climate such as Egypt to improve air flow around multiple rows of buildings. This study presents several types of courtyard designs inside houses that provide direct air flow at windward sides inside compactly planned buildings. Next, air flow is described around one individual building and two buildings that have a passage between them. Furthermore, air flow around buildings is discussed to include several rows of buildings that range from rectangular linear to square shapes with flat and jack roofs, where the main goal is to achieve appropriate wind velocity at inlet surfaces, especially at the second and the third rows of buildings, and to avoid turbulence zones caused by wind around building. Finally, the effect of topography and urban mass on global wind velocity at the city scale is discussed.
\end{abstract}

Keywords: Hot Climate, Courtyards, and Air Flow due to Wind Pressure around Buildings, Thermal Comfort with Natural Ventilation

\section{Introduction}

This paper focuses on the previous study that related with wind flow around the different arrangements of buildings. Linear buildings are the main subject of this survey. Configuration of linear buildings forms between buildings around inner-courtyards and rows of multiple buildings. Unfavorable zones due to flow pattern performance are formed as a result of wind faced buildings. This survey study presents the previous solutions that can solve these zones. Aerodynamics shapes of buildings, chess -board arrangements of building rows, and jack roofs can decrease the effects of these zones. Many other solutions as open ground floor to decrease the unfavorable effect of stagnation zones in the wind-ward side of the buildings are not discussed in this review article. Also, the effect of the wind velocity due to Beaufourt scale is not discussed in this paper. Strong wind is completely different than weak wind in air flow around buildings.

\subsection{Wind Flow Problem}

The article can describe the main problem of air flow around multiple buildings due to wind direction. Multiple buildings have a major problem related to air flow. First row of multiple rows of buildings that faced wind has maximum amount of wind. Next rows without carefully studying the fundamental of wind flow manners with buildings may have minimum amount of wind. Unfavorable wind movement due to wind direction is at inlet openings. A major problem is caused by the first row. Vortex and recirculation movement are a major problem of the next rows of multiple buildings. The methodology to solve the problem is presenting the climatic problem and how can the natural ventilation solve this climatic problem physically. Also, the relationship between air flow and natural ventilation is discussing in this article. The previous studies that deal with buildings around innercourtyards, row of two buildings, multiple rows of buildings, and jack roofs are analyzed to solve the air flow problem that can affected directly in natural ventilation inside the buildings. Seriously, air flow around building is the main basic of natural ventilation that can achieve thermal comfort inside the buildings in the hot climate. 


\subsection{Climatic Problem Description}

High temperatures and intensive solar radiation in hot arid climates require compact planning of houses with minimum external surface area, small windows that face the wind direction, with most windows facing internal courtyards rather the exterior of the group and finally small courtyards, according to a U.S. military handbook [1]. To temper the effects of these harsh environmental conditions, building design often maximizes the use of compact planning, which reduces and delays the effect of external heat gains [2] due to mutual shading. On the other hand, this compact planning of buildings leads to a significant reduction of available wind velocity for natural ventilation. In addition, urbanization has increased drastically and it is expected that there will be twenty-two mega cities by 2015 . Urban areas are warmer than surrounding rural areas due to the urban heat island effect where bare soils and vegetated surface are replaced by concrete structures and pavements which absorb and store more heat from the sun than the original surfaces. Urban heat island effect is further enhanced by exhaust heat associated with human activities such as air conditioning and manufacturing [3].

\subsection{Physical Problem Solution}

Indoor air velocity in a hot climate acts to cool the occupants by two ways. First, it cools the occupant directly by increasing the convective and evaporative heat transfer from the body surface. Second, it cools the occupant indirectly by removing heat stored in the building [4].

A study on natural ventilation in Thailand [5] revealed that the permissible zone temperature of thermal comfort can be extended to $29^{\circ} \mathrm{C}, 30^{\circ} \mathrm{C}, 31^{\circ} \mathrm{C}$ for indoor air velocities of $0.2 \mathrm{~m} / \mathrm{s}, 0.4 \mathrm{~m} / \mathrm{s}, 1 \mathrm{~m} / \mathrm{s}$ instead of air temperatures that range from $21^{\circ} \mathrm{C}$ to $26^{\circ} \mathrm{C}$ as suggested by ASHRAE Standard 55-2004. The same study further observed that thermal comfort can be achieved inside houses in a Bangkok suburb during $20 \%$ of the year by providing houses with indoor air velocity of only $0.4 \mathrm{~m} / \mathrm{s}$. Although this is not a large number, it is worth pursuing, because natural ventilation has very low operating cost in the presence of acceptable indoor air velocities.

Another study on the effect of indoor air velocity on thermal sensation [6] observed that air movement reduced discomfort from heat above $31{ }^{\circ} \mathrm{C}$ and can achieve a predicted mean vote of $\mathrm{PMV}=+1$ on the sensation scale and for temperatures above $40^{\circ} \mathrm{C}$ thermal sensations between +2 to +3 can be achieved for velocities over $0.25 \mathrm{~m} / \mathrm{s}$.

But in the case of excessive temperatures $\left(\geq 31^{\circ} \mathrm{C}\right)$, air velocities cannot achieve optimum thermal comfort for two reasons: The first reason is related to the occurrence of draft discomfort for high air velocities above $1.5 \mathrm{~m} / \mathrm{s}$. The second reason is related to the sensation scale, this scale indicates that completely thermal comfort cannot be achieved at high temperature over $35^{\circ} \mathrm{C}$ even with higher indoor air velocity as proposed by ASHRAE Standard 55 [7] . Fig. 1 shows the relationship between increasing air velocity and decreasing sensation scale at the high temperature and also shows the limitation of indoor air velocity (peak point) $2 \mathrm{~m} / \mathrm{s}$ than portable wind velocity 4 $\mathrm{m} / \mathrm{s}$.

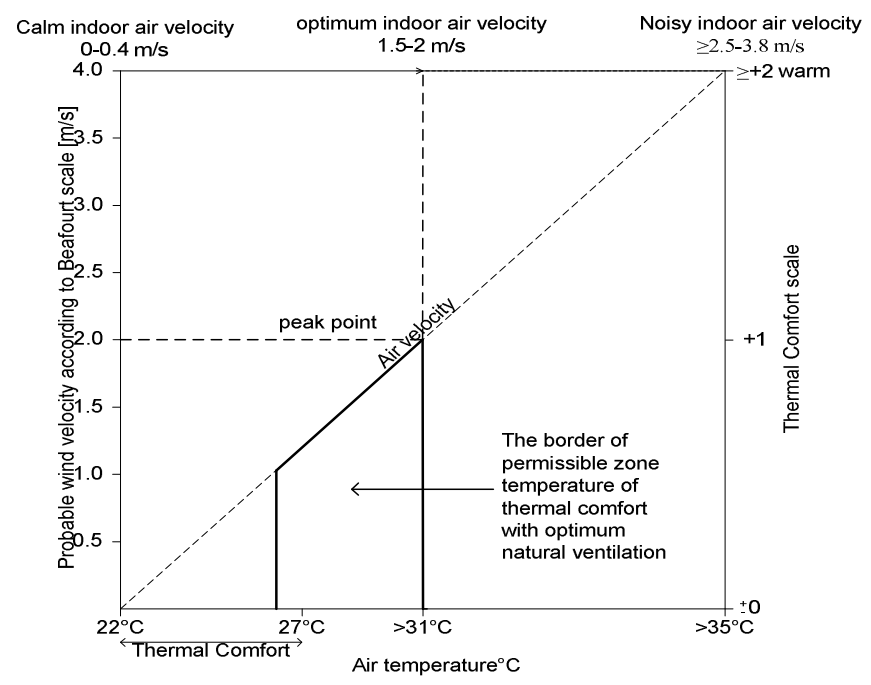

Figure 1: Relationship between thermal comfort scale and air velocity from [6].

A U.S. utility company has indicated that each $1^{\circ} \mathrm{F}$ increase in summer cooling temperature set point will save 3-4 \% of air conditioning and has shown also that mechanical air-conditioning of residences costs 11 times more than natural ventilation due to wind pressure [8]. Fig. 2 shows the approximate relationship between both HVAC and natural ventilation with cooling energy cost. The cost increases if using HVAC at high temperature and decrease if using natural ventilation at the same temperature.

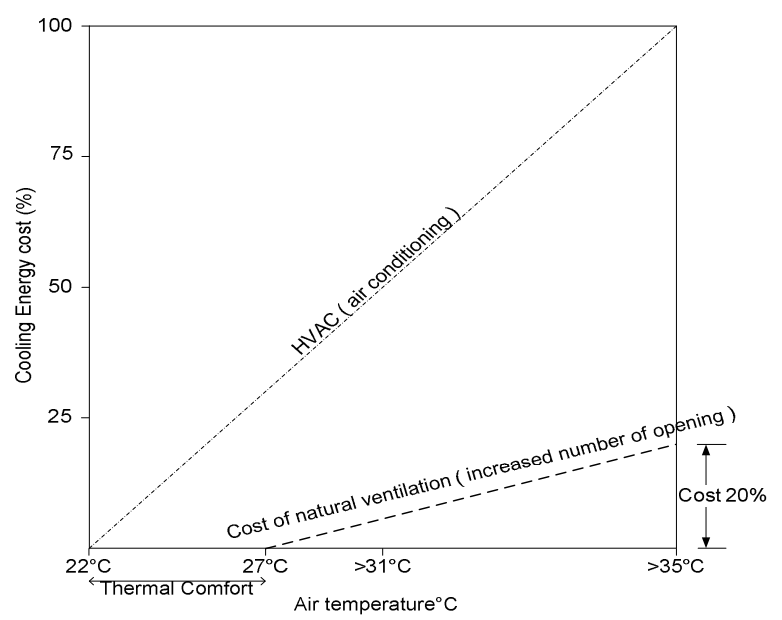

Figure 2: Relationship between both HVAC and natural air movement with cooling energy cost from [7] and [8].

\subsection{The Relationship between Air Flow around Buildings and Cross Ventilation from ASHREA handbook Fundamentals, [22].}

Ventilation depends on the different pressure between intake surface that is at windward side of building and 
exhaust surface that is at leeward side of building. Recirculation and vortex or stream pattern flows can affect non-preferably on intake and exhaust surfaces of building. Beside air flow patterns around building, climatic conditions, such as wind velocity and direction, and building dimensions can affect also on cross ventilation or infiltration rate inside building.

Equation no -1 shows that the relationship between air flow around buildings and natural ventilation.

$\mathrm{P}_{\mathrm{s}}=\mathrm{C}_{\mathrm{p}} \mathrm{P}_{\mathrm{v}}$

$\mathrm{P}_{\mathrm{s}}=$ Different pressure between the pressure in the two surfaces of building.

$\mathrm{C}_{\mathrm{p}}=$ Local wind pressure coefficient that is according to patterns of air flow around buildings, terrain category, climatic condition, and building dimensions.

$\mathrm{P}_{\mathrm{v}}=$ Wind velocity pressure that is according to The height of building according to the ground level, air density, and gravitational constant.

\section{Courtyards}

The first approach to improving airflow due to wind pressure is to increase the inlet surface areas on the windward side. The first surface is at the external border of the building that faces wind directly. The second surface is at the internal border of the building that lays on the courtyard and faces the wind indirectly.

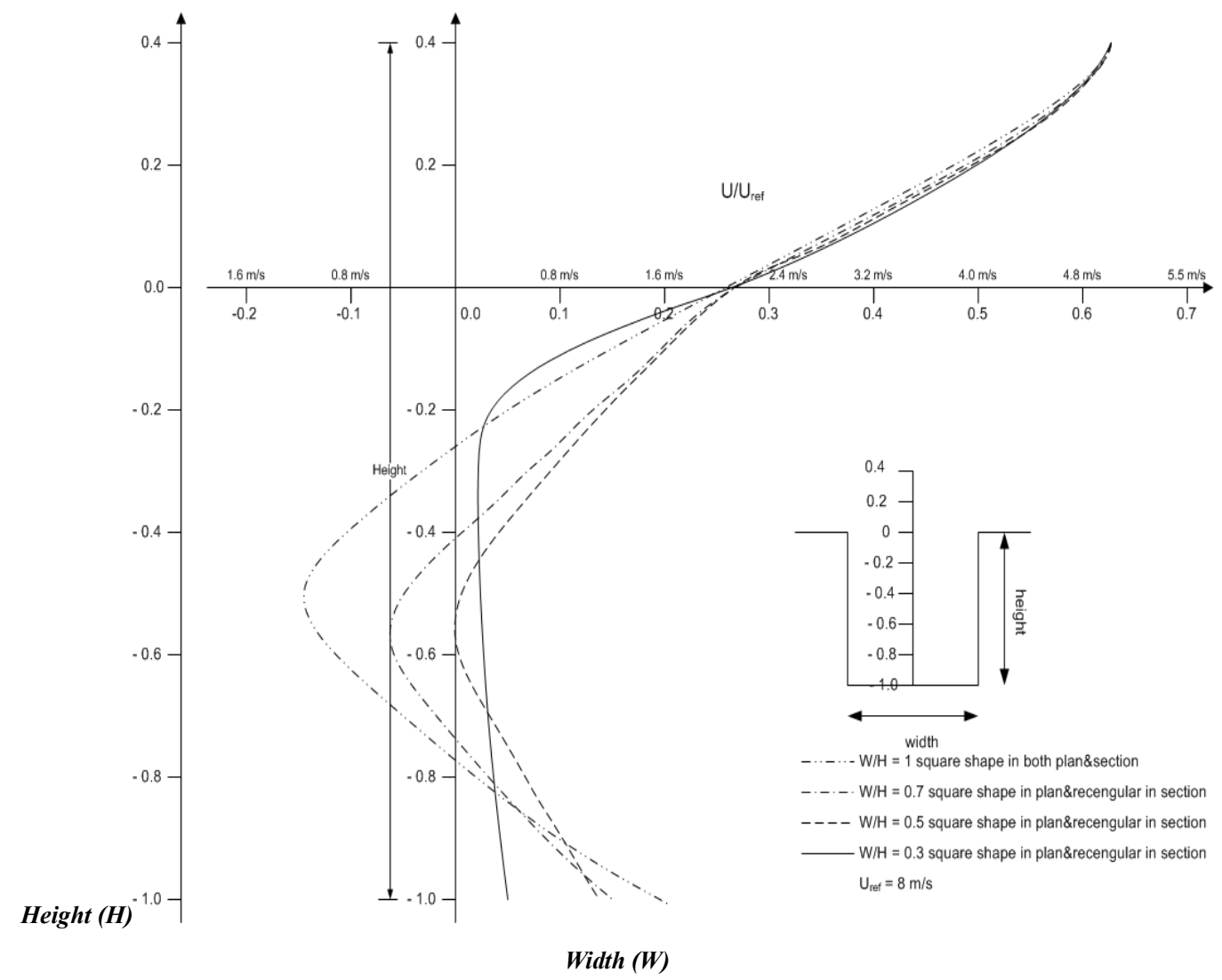

Figure 3: Comparison of U/U reffor four ratios of width/height 1, 0.7, 0.5, and 0.3 for a courtyard from [10].

Naroyan [9] presents an Indian case study in Jaipur City in which multiple elements were integrated (wind tower, courtyard, and chimney) to create natural ventilation inside houses at high ambient temperatures of over $40^{\circ} \mathrm{C}$. The integrated courtyard can achieves a fraction of $20 \%(1.2-2$ $\mathrm{m} / \mathrm{s})$ of the wind velocity $(6-8 \mathrm{~m} / \mathrm{s})$ and can reduce the outside air temperature ${ }^{1}$ by $20 \%$ of the Celsius scale value [9].

A study of an old city center in Havana, Cuba investigates the effect of four ratios of courtyard width to

\footnotetext{
${ }^{1}$ This high value of reducing external air temperature is due to building thermal mass which reduces and delays the effect of external heat gains beside natural ventilation.
}

height: $0.3,0.5,0.7$, and 1 , which achieve air velocity fractions of $+4 \%$, zero air velocity, $-5 \%$, and $-15 \%$ of the wind velocity $\left(\mathrm{U}_{\mathrm{ref}}\right)$ at the midpoint of both width and height of courtyard ${ }^{2}$. Fig. 3 shows the four ratios of width to height according to a reference velocity of $U_{\text {ref }}=8 \mathrm{~m} / \mathrm{s}$ at over ten meters height [10].

A Chinese study of a courtyard in group of buildings in Beijing suggests a new geometric dimension of courtyard characterized by a small width that faces the wind direction and long length that parallels with wind direction. The

\footnotetext{
${ }^{2}$ Although, it is not clear that the represented negative wind velocity due to changed direction or recirculation inside courtyard at the middle height of building. In any case this is not a favorable condition of using courtyard in high wind velocity.
} 
courtyard behaves like an air tunnel to increase low wind velocities in Beijing. The courtyard is used in six-story buildings (20 meters). The six story buildings are in the south and tall buildings ( 40 meters) are in the north because of the orientation of the prevailing N-S wind in the summer in Beijing. It is observed that in the northern wind case the air velocity ranges from $0.1-0.4 \mathrm{~m} / \mathrm{s}$, which is too low to support natural ventilation of the apartments. This reduction of air velocity occurs because the six-story buildings are in a recirculation zone, created by the tall building to the north. When wind comes from the south, the air velocity around the six-story buildings was higher but still low, between $0.3-0.8 \mathrm{~m} / \mathrm{s}$ because of the small distance between one building to another at the south that deflects wind before it reaches the next one [11]. Fig. 4 shows the layout of two buildings that includes the longer courtyard to increase wind velocity and thus to ventilate the large area as much as possible for these units of six-story buildings.

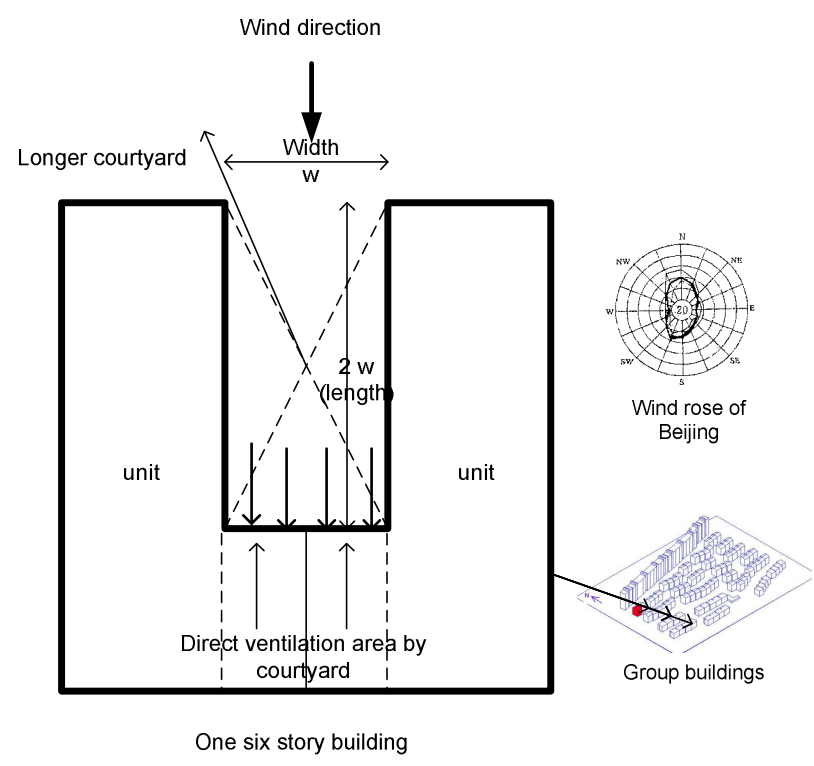

Figure 4: Longer courtyard of two units of six-story building from [11]

\section{Air Flow around Multiple Building Configurations}

\subsection{Air Flow around Individual Rectangular Buildings}

To improve air flow around multiple buildings, the different zones around building that occur by wind velocity or wind pressure need to be analyzed. The main turbulence zone that occurs behind the building on the leeward side of the building is called wind vortex or wake. The length of this zone depends on the dimensions of building. The secondary turbulence zones that occur in front of building are at the ground level, roof, and two sides [12].

There are four main pressure zones around a building: For the first zone in front of the building, the maximum positive pressure is at the upper level of the building at approximately $70 \%$ of the building height, the negative pressure is at approximately $30 \%$ of the building height from the ground level; between the positive and negative pressures, there is a point of zero velocity and pressure. For the second zone in the back of the building, the maximum negative pressure is at both lower level of building and near the back of the building; the negative pressure decreases and the positive pressure begins to increase with increasing distances from the ground. For the third zone at the roofline of the building, the maximum negative pressure is towards the wind direction, with decreasing negative pressure along the wind direction. The final and fourth zone is at the two corners or sides of the building, standing vortices occur near these corners [13 $]^{3}$. Figure 5 shows the different pressure zones around the building in a section view.

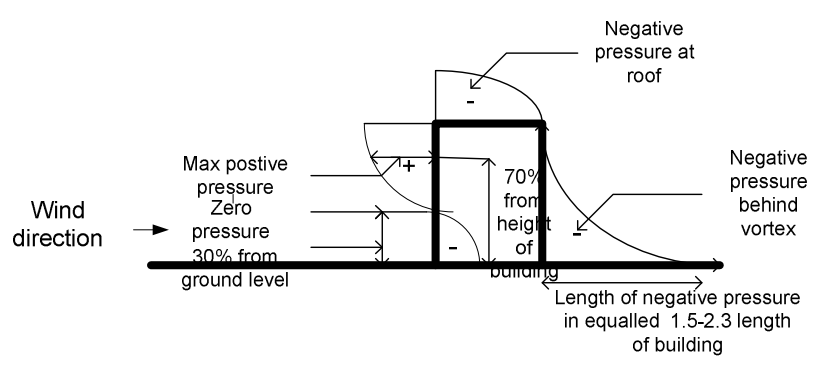

Figure 5: Pressure zones around building from [13]

Table (1) shows the patterns of air flow around building according to ASHREA handbook fundamentals, [22], the pressure zones consists of two main zones. The first zone is at in front of building. The second zone is at behind the building.

Table (1) The pressure zones that caused by wind

\begin{tabular}{|c|c|c|c|}
\hline $\begin{array}{l}\text { Pressure } \\
\text { zones }\end{array}$ & $\begin{array}{l}\text { Zones } \\
\text { according to } \\
\text { building }\end{array}$ & Patterns & $\begin{array}{l}\text { Positions } \\
\text { according to } \\
\text { ground level }\end{array}$ \\
\hline \multirow{6}{*}{$\begin{array}{l}\text { Pressure } \\
\text { zones } \\
\text { according } \\
\text { to wind and } \\
\text { building. }\end{array}$} & \multirow{4}{*}{$\begin{array}{l}\text { In front of } \\
\text { building }\end{array}$} & Upwind vortex & $\begin{array}{l}\text { At the lower } \\
\text { level. }\end{array}$ \\
\hline & & Stagnation zones & $\begin{array}{l}\text { At the middle } \\
\text { level. }\end{array}$ \\
\hline & & Stream lines & $\begin{array}{l}\text { At the roof of the } \\
\text { building. }\end{array}$ \\
\hline & & Unaffected zones & $\begin{array}{l}\text { Over the roof of } \\
\text { the building. }\end{array}$ \\
\hline & \multirow{2}{*}{$\begin{array}{l}\text { Behind } \\
\text { building }\end{array}$} & $\begin{array}{l}\text { Recirculation } \\
\text { zones }\end{array}$ & $\begin{array}{l}\text { At the lower and } \\
\text { middle level. }\end{array}$ \\
\hline & & $\begin{array}{l}\text { Contaminated } \\
\text { zones }\end{array}$ & $\begin{array}{l}\text { At the higher } \\
\text { level. }\end{array}$ \\
\hline
\end{tabular}

Further studies concentrate on aerodynamic shapes such as vessels and wheels shapes. These suggested shapes can decrease all turbulence zones from $50 \%$ to $70 \%$ because of a reduction of the area that directly faces the wind direction through the use of rounded shape [14], [15]. Figure 6 shows the effect of aerodynamics shapes on wind flow.

3 At lower level of windward side of building, recirculation may occur. 


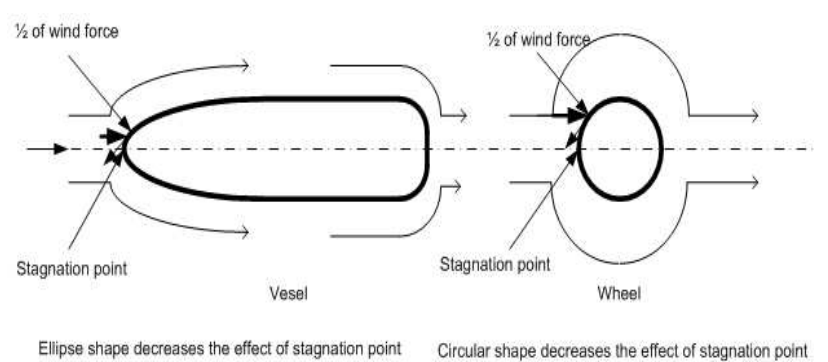

Figure 6: The effect of aerodynamics shapes from [14] and [15].

\subsection{Air Flow around Two Buildings}

Using the passage between two parallel buildings, similar to a Venturi nozzle, is a solution to improve wind flow on the windward side of buildings, yet two separate standing vortices in front and behind of buildings can be observed, the back vortices are three times as long as the long side that faces the wind ${ }^{4}$; these vortices increase when the passage between buildings decreases and two separate corner streams can be observed also. This result is concluded from two papers, the first one is by Baskarans \& Kashef [12] and the second one is by Blocken \& Carmeliet [13]. Fig. 7 shows the turbulence zones that occur at different distances of passage.

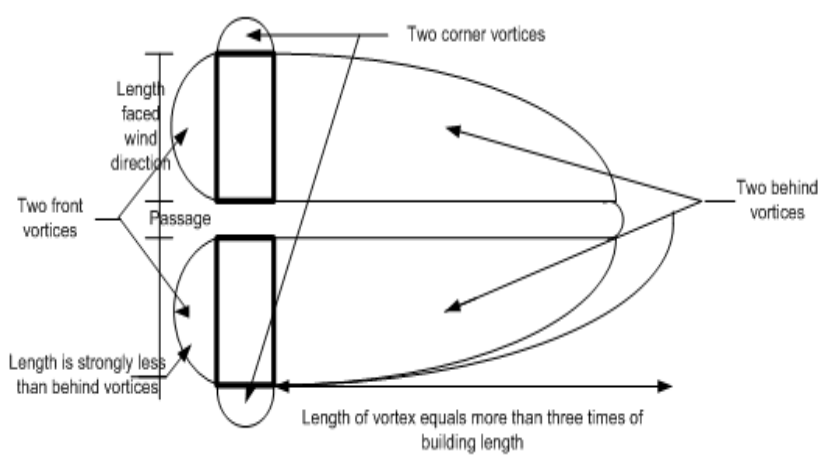

Figure 7 The effect of narrow passage on increasing turbulence zones from [12].

\subsection{Air Flow around Multiple Building Rows}

The first solution to improve wind flow at windward side of building rows is to provide a narrow and long passage between building rows. It is observed that air velocity increases in the passages between buildings and can achieve $60-150 \%$ of the wind velocity. Air velocity at the middle distance of passages between buildings is higher than the other position of inlet surfaces at wind ward side. It is also observed that the air velocity is higher at the first row compared to the second row and similarly for the second and third rows. Fig. 8 shows the effect of narrow passage on increasing wind velocity at different rows [12].

The second solution to improve wind flow at inlet surfaces, i.e., the windward side of a building starting from second row up to seven row is to increase the distance in both

\footnotetext{
${ }^{4}$ The length of behind vortex depends on the height and the width beside the length of building.
}

directions $\mathrm{x}$ and $\mathrm{y}$. Complex flow pattern may occur with multiple recirculation wakes within the gap regions and channel effect near the inlet plane of the block system [16].

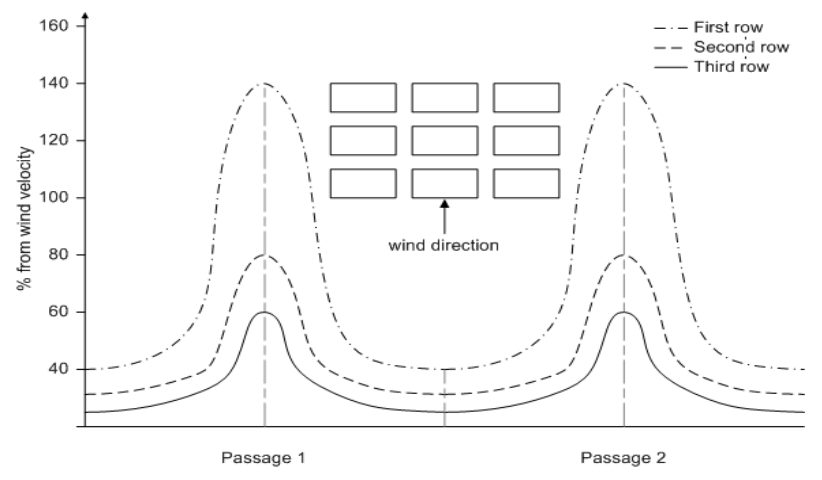

Figure 8: Wind velocity at both inlet surfaces and passages for three rows from [12].

The third solution to improve air flow at inlet surface in the far building row is the chess board arrangement. To improve wind flow in the last row, the solution increases the distances between buildings to achieve two times the length of the building in direction $y$ and one time the length of the building in direction $\mathrm{x}$ at a rectangular shape. In a square shape, the solution keeps the distance between buildings to achieve two times of the length of the building in the cavity in direction $y$ but decreases passage in the direction $\mathrm{x}$ to less than half of the length of the building. Both square and rectangular shapes arranged in a chess board pattern increase wind velocity. It can be observed that both shapes achieve a suitable wind velocity starting from second row, but rectangular buildings have achieved better natural ventilation than square buildings, although square buildings achieve higher wind velocity than rectangular because of the narrow passage between square buildings [5]. Fig. 9 shows the increasing distance between buildings in the chess board system to arrange buildings that can improve the wind flow at the second and subsequent rows.

The fourth solution concentrates on the effect of the jack roof inside the courtyard between two units in different wind directions. Therefore, this experiment presents two types of roofs, the first one is a jack roof and the second one is a flat roof. This experiment tests the effect of the two types of roofs inside a courtyard. It can be observed that the positive pressure increases more strongly in jack roof arrangement than the flat roof arrangement ${ }^{56}$ as shown in Fig. 10 [4].

\footnotetext{
${ }^{5}$ Pressure coefficient depends on many factors such as: 1) pressure of front or back surfaces according to wind direction that this pressure depends on the wind velocity and the surface area that faced wind (constant); 2) wind direction $(\theta)$; 3) Height of courtyard ( $\mathrm{Hc})$; 4) Courtyard spacing ( $\mathrm{Sc}$ ). Because the coefficient of pressure depends on variety of factors, it has been represented in tabular form for use by designers.

${ }^{6}$ The main aim of increasing positive pressure is to improve air flow at inlet sides of buildings that lay on inner courtyard, because natural ventilation depends on positive at inlet sides of buildings and negative pressure at outlet sides of buildings. In low wind velocity and hot climate prefer increasing air flow inside buildings that depends on the difference between positive and negative pressure.
} 

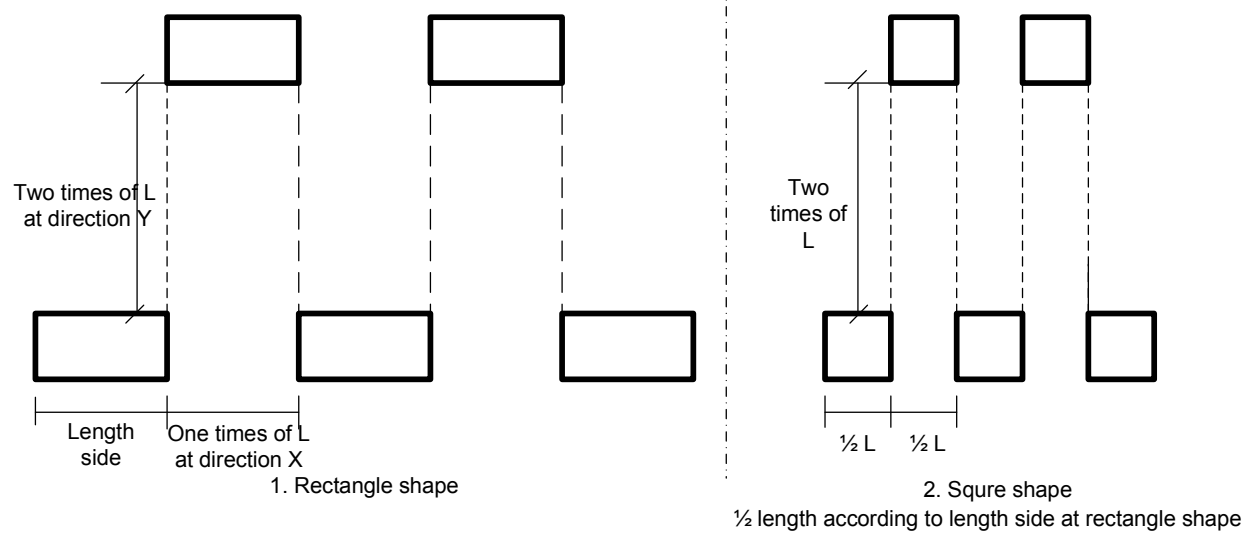

Figure 9: Groups of buildings shows increasing distance, narrow passage, and chess board arrangement from [5].

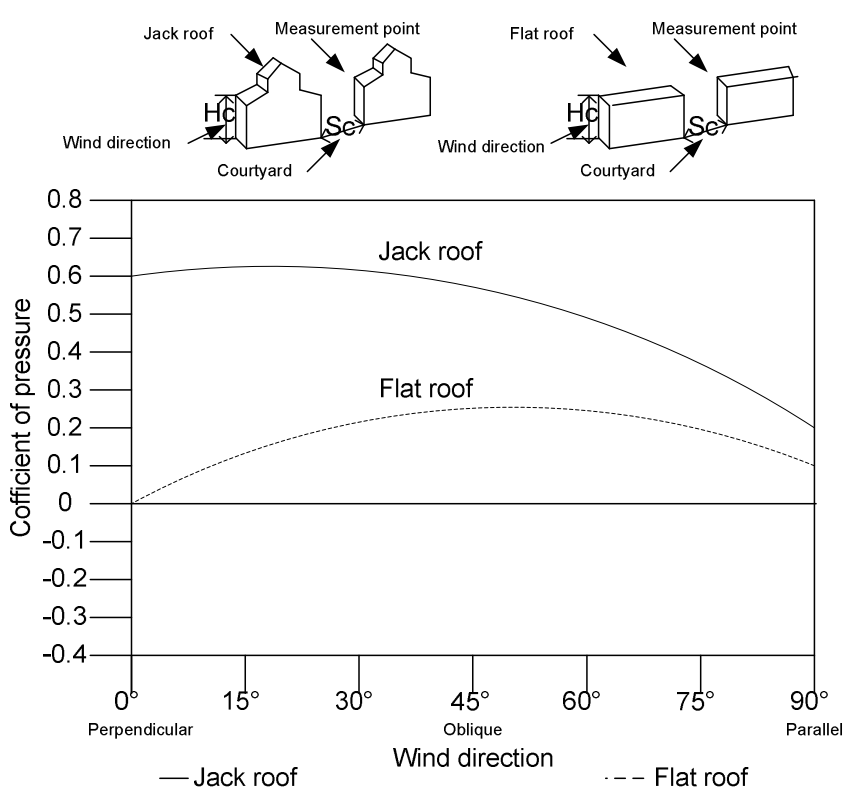

Figure 10: Comparison between jack and flat roof on coefficient of positive pressure [4].

\section{Airflow at Urban Area Planning Scale}

To improve airflow due to wind pressure at inlet surfaces, i.e. windward sides of buildings and create sufficient positive pressure at these surfaces, the initial prevailing wind with its velocity needs to be maintained and turbulence zones need to be avoided before blowing to the urban area. The main effects on wind are topography and man-made structures, i.e., buildings.

\subsection{Topographic Effects}

At times, mountains have unfavorable effects on the prevailing wind especially when mountains faced the wind direction, in spite of the fact that the wind velocity increases two times on the top of mountains. It can be observed that the reduction of wind velocity behind mountains is up to $50 \%$ of the initial value. This reduction was observed in the urban area of Seoul according to the Korean experiments [17]. Mountains also cause turbulence zones, i.e., vortices in the zones behind the mountains relative to the wind direction. The large vortices by mountains were shown to affect the urban area in South Korea [18].

Another effect of mountains is that they cause stagnation, i.e., complete elimination of wind velocity and dispersion of wind outside the urban area. These complete reductions of wind velocity were observed at urban area in Salt Lake City ${ }^{7}$ [19]. Fig. 11 shows the unfavorable effect of mountains on wind flow at the urban scale.

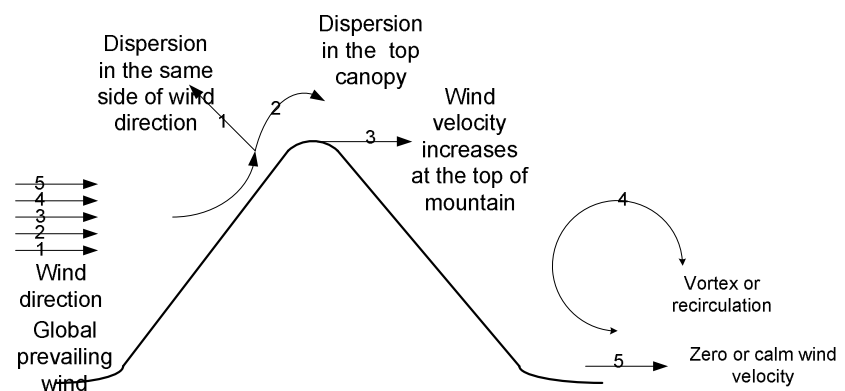

Figure 11: The effect of mountains on global prevailing wind from [17], [18], and [19].

\subsection{Building Effects}

The first row of buildings affects the second row located behind it relative to the wind direction. It causes recirculation in front of the second row. This vortex occurs because the wind converged downstream at the windward side of building and diverged upstream at the roof of building, this diversion occurs especially with flat roofs. This vortex may occur even when increasing the distance

\footnotetext{
${ }^{7}$ The unfavorable effects of mountains depend on many factors such as wind direction and site of urban mass. But the mountains sometimes can create better conditions for natural ventilation, for example, if the layout of urban mass lies between two mountains. The mountains can be favorable for natural ventilation because they can create air passages (channel) between them.
} 
between multiple rows to achieve three times of the height of building. Fig. 12 shows the effect of first row of urban mass to cause recirculation at the cavities between second and third rows [3].

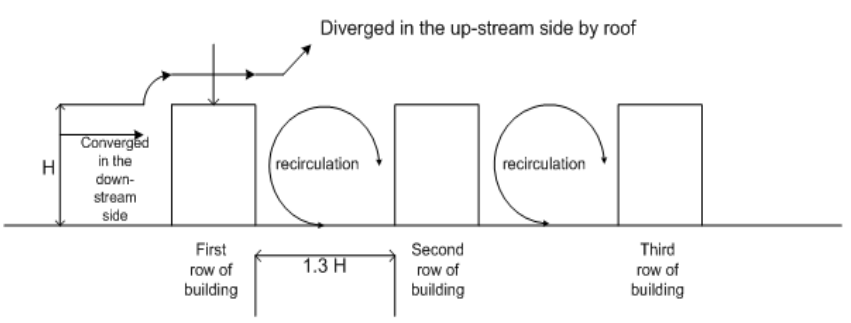

Figure 12: Effect of roofs on the cavities between multiple rows from [3].

Another effect of buildings is the effect of urban mass. To decrease unfavorable effect of building rows and urban masses, one solution is to stagger the building rows or urban masses. Fig. 13 shows the unfavorable and favorable of urban masses effect.

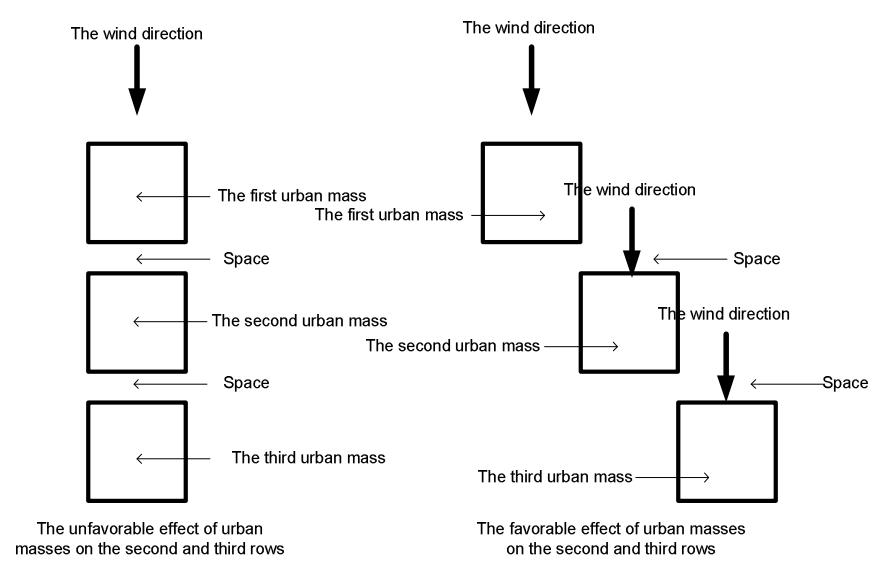

Figure 13: Effect of the first urban mass on the second one

The effect of urban masses can decrease the prevailing wind to less than one quarter of the global wind at the height of 20 meters from the ground level [20]. Fig.14 illustrates the comparison between urban wind and global wind.

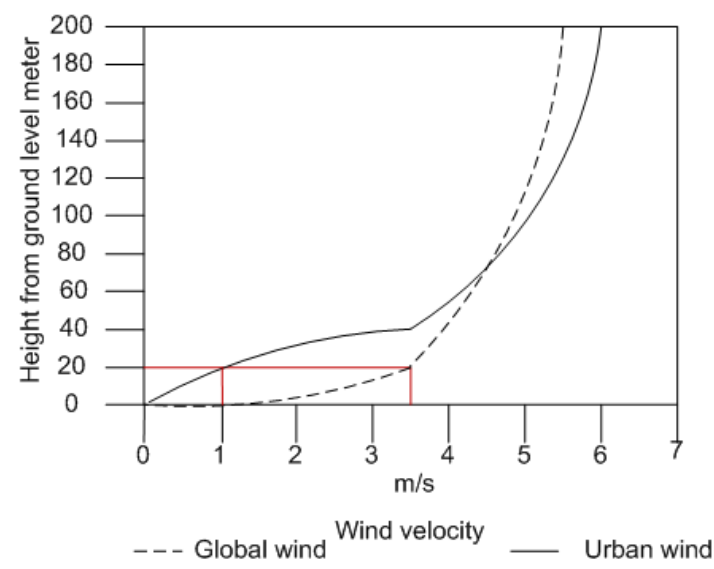

Figure 14: Comparison between global and urban wind from [20].

\section{Conclusions and Summary}

\section{Thermal Comfort \& Wind Velocity}

Natural ventilation due to wind induced airflow can achieve both thermal comfort and reduction of cooling energy cost over the year with only $0.4 \mathrm{~m} / \mathrm{s}$ in slightly hot districts. This reduction depends on both outdoor air temperature and wind velocity in hot and arid areas. There is a limitation of using wind velocity that is over $2 \mathrm{~m} / \mathrm{s}$. If more velocity is needed, it should be provided above the height of a person $(2 \mathrm{~m} / \mathrm{s})$ from the floor or integrated with other natural passive cooling strategies such as high thermal mass and evaporative cooling or integrated with mechanical cooling. When applying these methods, if the outdoor temperature is over $40^{\circ} \mathrm{C}$, a value of +2 and +3 on the thermal sensation scale (warm sensation) can be achieved with suitable air velocity.

\section{Air flow Inside Courtyards}

The integrated closed courtyard with wind catcher and chimney can achieve only $20 \%$ of the freeflow wind velocity along the wide dimension of the courtyard. Another study of closed courtyard observes negative airflow velocities inside the courtyard (recirculation movement) especially in the presence of high wind velocity. The last study of courtyards characterized by a small width and long length may achieve higher velocities than the first solution, this can be a future study to solve hot climate in locations such as Farafra Oasis in Egypt, and this solution is suitable to high outdoor temperature with low wind velocity.

\section{Air Flow around Multiple Buildings}

Wind flow causes a vortex behind the building. This vortex depends on the dimensions of building especially the area that faces the wind. The length of this vortex ranges from one and half times to twice of the length.

Wind flow causes four different zones of pressure. The positive pressure is in front of the building and the negative pressure is at the roof, two corners, and behind, when negative pressure increases. The turbulence zone occurs because of the stagnation point that is located at the center of the building at the upper level; this point achieves maximum positive pressure. Therefore, aerodynamic shapes such as vessels and wheels can decrease both of positive pressure especially at the stagnation point in front of this shape and the maximum negative pressure around the other zones of this shape. A future study will concentrate on aerodynamic shapes in districts with high outdoor temperature and high wind velocity such as Farafra Oasis, Egypt. Natural ventilation depends on the difference between the positive pressure in the zone in front of the building and the negative pressure in the other three zones around the building especially behind the building. But airflow depends on both decreasing the turbulence zone that occures in front of the next row of the building 
especially with high wind velocity and increasing wind velocity that introduces to these next rows .

The first attempt to achieve high performance both in terms of airflow around buildings and natural ventilation inside building, uses a narrow passage that face the wind between two buildings to increase the Venturi effect; yet the passage also increases the length of the back vortex to more than three times of length of the building. This attempt is suitable to districts that have low wind speed like Aswan.

Table (2) Summary of results

\begin{tabular}{|c|c|c|}
\hline Item & The effects & The evaluation according to natural ventilation \\
\hline 1-Climatic elements. & $\begin{array}{l}\text { High wind velocity is preferable for hot } \\
\text { climate }\end{array}$ & $\begin{array}{l}\text { To achieve high air velocity at wind ward side of } \\
\text { building }\end{array}$ \\
\hline $\begin{array}{l}\text { 1-1- Wind velocity at wind ward } \\
\text { side of building. }\end{array}$ & According to thermal comfort & $\begin{array}{l}\text { Tools : wind velocity and direction, passages, cavities, } \\
\text { and arrangement of buildings }\end{array}$ \\
\hline $1-1-1-0.2 \mathrm{~m} / \mathrm{s}$ & It can achieve thermal comfort up to $29{ }^{\circ} \mathrm{C}$. & $\begin{array}{l}\text { Narrow passage and chess board arrangement are } \\
\text { required to achieve Venturi effect. }\end{array}$ \\
\hline $1-1-2-0.4 \mathrm{~m} / \mathrm{s}$ & It can achieve thermal comfort up to $30^{\circ} \mathrm{C}$. & $\begin{array}{l}\text { Preferable if accurate air flow around building can be } \\
\text { achieved. }\end{array}$ \\
\hline $1-1-3-\geq 1.0 \mathrm{~m} / \mathrm{s}$ & It can achieve thermal comfort up to $31{ }^{\circ} \mathrm{C}$. & Moderate passage is required. \\
\hline $1-1-4-\geq 1.5 \mathrm{~m} / \mathrm{s}$ & It can achieve draft discomfort. & Avoid Venturi effect. \\
\hline $\begin{array}{l}1-2-\quad \text { Wind direction at wind ward } \\
\text { side of building. }\end{array}$ & $\begin{array}{l}\text { Perpendicular wind direction at wind ward } \\
\text { side is preferable for hot climate. }\end{array}$ & It can control in wind velocity at windward side. \\
\hline $\begin{array}{l}\text { 1-2-1-Perpendicular with wind } \\
\text { direction. }\end{array}$ & $\begin{array}{l}\text { It can achieve maximum air velocity at } \\
\text { windward side ( } 50-70 \% \text { from wind } \\
\text { velocity) }\end{array}$ & Preferable in extreme hot climate. \\
\hline 1-2-2- Slope with wind direction & $\begin{array}{l}\text { It can achieve moderate air velocity at } \\
\text { windward } \operatorname{side}(30-40 \% \text { from wind } \\
\text { velocity). }\end{array}$ & Preferable in moderate climate. \\
\hline 1-2-3-Parallel with wind direction & $\begin{array}{l}\text { It achieves low air velocity at wind ward } \\
\operatorname{side}(10 \% \text { from wind velocity). }\end{array}$ & Non-preferable in hot climate. \\
\hline 1-3-Outdoor air temperature & It is related to air velocity & $\begin{array}{l}\text { Outdoor temperature and wind velocity can determine } \\
\text { the required air velocity at windward side }\end{array}$ \\
\hline $1-3-1-\geq 31 \circ \mathrm{C}$ & $\begin{array}{l}\text {-Air velocity can achieve predict mean vote } \\
\text { PMV=+1 with maximum air velocity that } \\
\text { equals } 1.4 \mathrm{~m} / \mathrm{s} \text {. }\end{array}$ & It can achieve nearly thermal comfort. \\
\hline $1-3-2-\geq 40 \circ \mathrm{C}$ & $\begin{array}{l}\text {-Air velocity can achieve predict mean vote } \\
\text { PMV=+3 with maximum air velocity that } \\
\text { equals } 1.4 \mathrm{~m} / \mathrm{s} \text {. }\end{array}$ & It can achieve partly thermal comfort. \\
\hline 2-Building arrangements & According to wind velocity & It can increase or decrease wind velocity. \\
\hline 2-1-Narrow passage & $\begin{array}{l}\text { It can achieve over } 100 \% \text { from wind } \\
\text { velocity according to Venturi effect. }\end{array}$ & Preferable in low wind velocity case $0.4 \mathrm{~m} / \mathrm{s}$. \\
\hline 2-2-Chess board arrangements & $\begin{array}{l}\text { It can achieve around } 40 \% \text { from wind } \\
\text { velocity at the second and third rows. }\end{array}$ & Preferable in hot climate. \\
\hline 2-3- Jack roofs & $\begin{array}{l}\text { It can achieve around } 40 \% \text { from wind } \\
\text { velocity at the second and third rows. }\end{array}$ & Preferable in high wind velocity. \\
\hline \multicolumn{3}{|l|}{ 3-Courtyards } \\
\hline 3-1-Narrow courtyards & It causes negative pressure at courtyards. & $\begin{array}{l}\text { Courtyards as negative pressure (outlet side) at leeward } \\
\text { side are preferable in low wind velocity. }\end{array}$ \\
\hline 3-2- Wide courtyards & It causes positive pressure at courtyards. & $\begin{array}{l}\text { Courtyards as positive pressure (inlet side) at leeward } \\
\text { side are preferable in high wind velocity. }\end{array}$ \\
\hline 4- Urban wind (terrain category ) & $\begin{array}{l}\text { Obstacles that faced wind can decrease the } \\
\text { wind velocity up to } 50 \% \text { or more }\end{array}$ & $\begin{array}{l}\text {-Preferable in high wind velocity } 3 \mathrm{~m} / \mathrm{s} \text {. } \\
\text {-Non- Preferable in low wind velocity that is less than } \\
1.4 \mathrm{~m} / \mathrm{s}\end{array}$ \\
\hline
\end{tabular}

The second attempt shows the low wind velocity at the second and the third rows of linear buildings with narrow passage between them and suitable distance (cavity) between them. The wind velocity at the cavity achieves only $10-20 \%$ of wind velocity in the next rows and achieves $40 \%$ of wind velocity at the first row, while it achieves more than $60 \%$ at the passages. This attempt is suitable to low wind velocity with strong solar radiation ${ }^{8}$.

The third attempt arranges rectangular or square buildings in a chess board arrangement and suggests twice the length of the cavity according to wind flow with the passage being one unit length. It can achieve up to $40 \%$ of

\footnotetext{
${ }^{8}$ The narrow passage can cause both high wind velocities because of Venturi effect and low solar radiation that is preferable at hot climate such as most districts of Egypt.
} 
wind velocity at different rows. This is suitable in any climate conditions especially that demands compact planning to avoid strong solar radiation in very hot climates

The last attempt uses linear building with jack roof. It can achieve 0.2-0.8 according to wind direction of positive pressure at the cavity between rows. This attempt is suitable for high wind velocity with multiple linear building rows.

\section{Air Flow around Urban Area - Regional Planning- at City Scale}

Unfavorable conditions:-Mountains- that faced wind decrease global prevailing wind up to $50 \%$ and sometimes cause large vortices, although, the wind velocity increases at the top of mountains.

-Buildings cause recirculation in front of the next rows of buildings and decreases wind velocity up to $50 \%$ from real value because of the vortex that happens in the top of building- flat roof. The urban mass affects each other in away similar to what happens in the building rows.

Favorable conditions: According to topographic effects, the wind velocity can increase when the buildings lie between two rows of mountains. According to urban masses effects, the wind velocity can keep its velocity when the buildings are arranged in a staggered way to wind direction.

\section{Recommendations for Future studies}

This paper shows improved natural ventilation around multiple rows of rectangular buildings in hot climate at Thailand, India, Cuba, South Korea, and Salt Lake City similar to Aswan and Farafra in southern Egypt.

The paper also shows how to select the locations of future buildings according to topographic and building effects. It also shows how to arrange the future buildings, for example, in chess board arrangement to benefit the Venturi (channel or passage) effect to increase wind velocity. It suggests the suitable distance between future buildings, the long length is to decrease wind recirculation and the smaller or narrow passages is to increase wind velocity.

The paper also shows the benefit of aerodynamic shapes to decrease the unfavorable effect caused by stagnation pressure. Courtyards that have narrow width facing wind direction can be used to increase wind velocity and long length parallel to wind to collect wind, [21].

Fig. 15 presents the innovative study of solutions that applied in compact buildings at hot climate. Compact buildings are designed to avoid the unfavorable solar radiation. Chess- board arrangements of multible rows of buildings will be studied in future study at hot climate such as Aswan and Farafra oasis, Egypt.

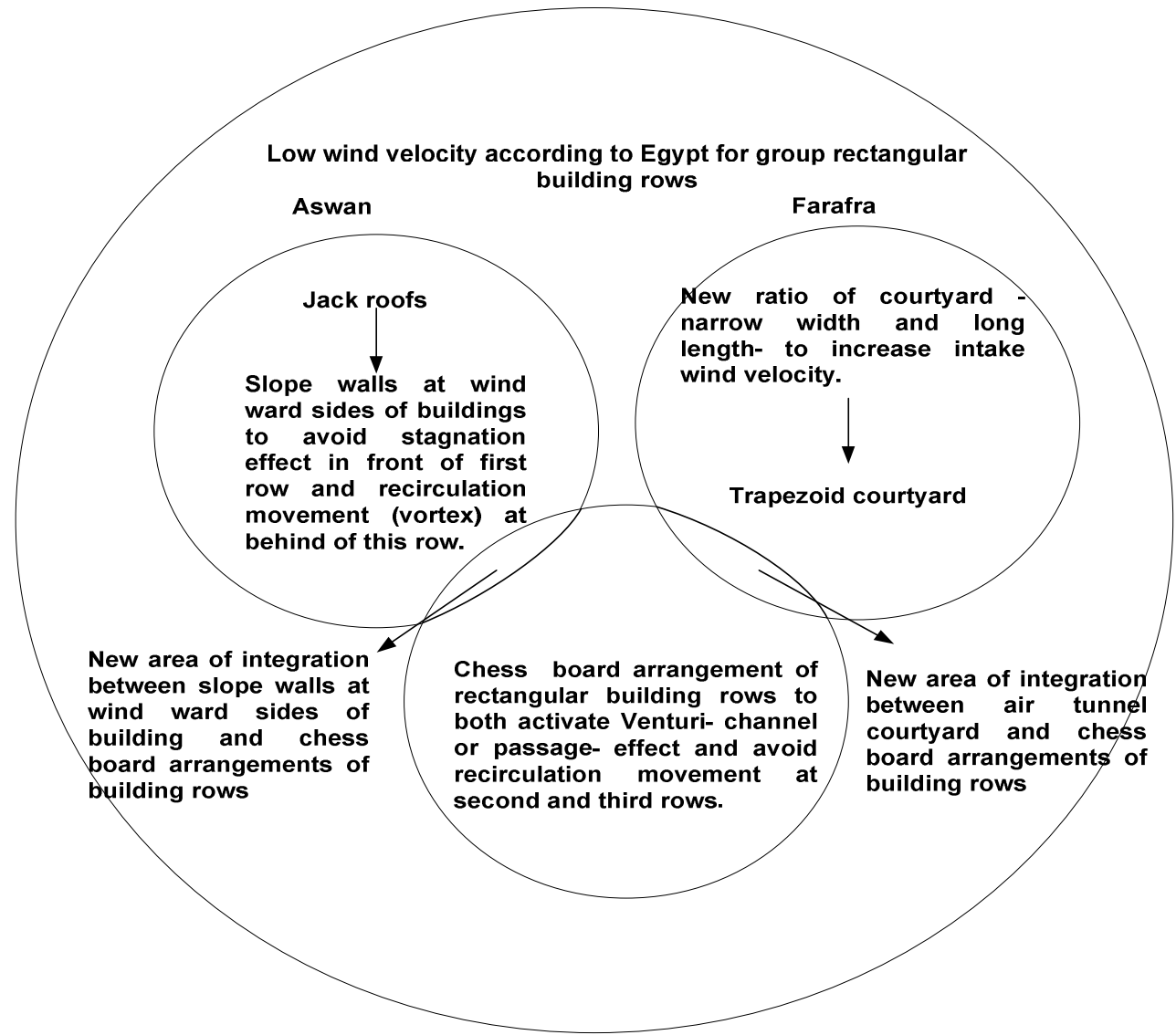

Figure (15) new interest areas of future studies to improve wind flow around buildings for hot climate cities with low wind velocities at Egypt. 


\section{References}

[1] Military Handbook, 2004, Cooling Building by Natural Ventilation, Department of Defense, Approved for Public Release, USACE Publication Depot, pp 7.

[2] Brown, G.P., 2000, Sun, Wind, and Light; Architectural Design Strategies, $2^{\text {nd }}$ Edition, John Wiley \& Son Publishers.

[3] Yamada, T. , 2005 , Numerical Simulation of Air Flows in and around A City in A Coastal Region, American Meteorological society, Annual Conf. , San Diego, California .

[4] Bauman, F., Ernest, D. , and Arens , E. A. , 1988, The Effects of Surrounding Buildings on Wind Pressure Distributions and Natural Ventilation in Long Building rows, Center for The Built Environment, University of California, Berkeley Publishers, Scholarship Repository .

[5] Tantasavasdi, C., Srebric, J., and Chen, Q., 2001, Natural Ventilation Design for Houses in Thailand, Energy and buildings, Vol. 33, Issue 8, pp $815-824$.

[6] Heidari, S., 2005, Effect of Air Movement in Buildings, Passive and low Energy Cooling for the Built Environment International Conf.

[7] Brager, G.S. , and de Dear, R., 2001, Climate, Comfort, \& Natural Ventilation : A New Adaptive Comfort for ASHRAE Standard 55, , Center for The Built Environment, University of California , Berkeley Publishers, Scholarship repository .

[8] Aynsley, R., 2002, Energy with Indoor Air movement, International Journal of Ventilation, Vol. 1, pp 33-38.

[9] Narayan, T., A Passive Courtyard Home in Jaipur, India: Design Analysis Thermal Comfort in A Hot Desert Climate, Arizona State University Publishers.

[10] Tablada, A., Blocken, B., Carmeliet, J., De Troyer, F., and Verschure, H., Geometry of Building's Courtyards to Favor Natural Ventilation: Comparison between Wind Tunnel Experiment and Numerical Simulation, leaven, Belgium.

[11] Chen, Q., 2006, Sustainable Urban Housing in China, Springer Publishers, Netherlands, pp 116-123.
[12] Baskaran, A., and Kashef, A., 1996, Investigation of Air Flow around Buildings Using Computational Fluid Dynamics Techniques, Engineering Structures Vol. 18, No 11

[13] Blocken , B. , and Carmeliet , 2004 , Pedestrian Wind Environment around Buildings : Literature Review and Practical Examples, Journal of Thermal Envelope and Building Science 28 ( 2 ) : 107- 159 .

[14] Popinet, S. , Smith, M., and Stevens, G. , 2003 , Experimental and Numerical Study of The Turbulence Characteristics of Air Flow around A research Vessel, Journal of Atmospheric and Oceanic Technology .

[15] Xia, J., Hussaini, M. Y., and Leung, D. , 2003 , Numerical Simulations of Wind Field in Street Canyons with and without Moving Vehicles , $16^{\text {th }}$ ASCE Engineering Mechanics Conference.

[16] Lee, R., Chan, S. T., Leone, J. M., Stevens, D. E., 1999, Air Flow and Dispersion around Multiple Buildings, $7^{\text {th }}$ International Conf. on Air Pollution, San Francisco, CA.

[17] Oh , S.N. , A Bio - climatic Assessment on Urban Area at Seoul Based on Observations and Numerical Simulations, Applied Meteorology Research Laboratory Publishers, Korea .

[18] Chung, Y.S. , and Kim, H. S., 2008, Mountain - Generated Vortex Streets Over The Korea South Sea, International Journal of Remote Sensing, Vol. 29, No. 3, pp $867-877$.

[19] Brown, M., Marty, L. , Calhoun, R., Smith, S., Reisner, J., Lee, B., Chin, S. , and De Croix, D. , 2001 , Multi-Scale Modeling of Air Flow in Salt Lake City and The Surrounding Region, ASCE Structures Congress Conf. , Washington, Dc .

[20] Leach, M .J. Chan, S. T., and Lundquist, J. K., 2005, HighResolution C F D Simulation of Air Flow and Tracer Dispersion in New York City, Sixth Symposium on The Urban Environment, Atlanta, GA.

[21] http://www.eere.Energy.Gov/buildings/energyplus/weatherd ata/1_africa_wmo_region_1/E . 